\title{
La dimensión religiosa de la existencia en la literatura romántica: el concepto de religión en "Geschichte eines Braminen" de Karoline von Günderrode en diálogo con Friedrich Schleiermacher
}

\author{
Montserrat Bascoy Lamelas \\ Universidade de Santiago de Compostela \\ montsebl@gmx.net \\ https://dx.doi.org/10.12795/futhark.2012.i07.01
}

\begin{abstract}
The literary work of Karoline von Günderrode deals, without a doubt, with the same ideological and aesthetic concerns that characterize the texts of the first Romantic writers. One of the key issues which have occupied these writers is redefining the concept of religion. In their works, they defend the need to recover the spiritual side of the human being, oppressed and denied by a materialistic and rational world and a morality that suppressed the true nature of man.

The theories of Friedrich D. E. Schleiermacher on true religion had a fundamental importance in the romantic thought. Like his contemporaries, Karoline von Günderrode also reflects in his writings on religious issues. In his story "Geschichte eines Braminen" can be seen, as shown in this paper, the influence of Schleiermacher's ideas on the concept of religion presented by the writer.
\end{abstract}

Keywords: Günderrode, Schleiermacher, religion, Romantic thought, individualism, divinity, perfectibility

Resumen: La obra literaria de Karoline von Günderrode manifiesta, sin duda alguna, las mismas preocupaciones ideológicas y estéticas que caracterizan los textos de los primeros autores románticos. Una de las cuestiones esenciales de las que se han ocupado estos escritores es la redefinición del concepto de religión. En sus obras es defendida la necesidad de recuperar la esfera espiritual del ser humano, oprimida y negada por una visión materialista y racional del mundo y por una moralidad que reprime la verdadera naturaleza del ser humano.

Las teorías de Friedrich D. E. Schleiermacher sobre la verdadera religión tuvieron una importancia fundamental dentro del pensamiento romántico. Al igual que sus contemporáneos, Karoline von Günderrode reflexiona también en sus textos sobre la cuestión religiosa. En su relato "Geschichte eines Braminen" puede observarse, como se muestra en este trabajo, la influencia

Futhark 7 (2012)

Bascoy, La dimensión religiosa, 9-42

ISSN 1886-9300 
de las ideas de Schleiermacher en el concepto de religión presentado por la escritora.

Palabras clave: Günderrode, Schleiermacher, religión, pensamiento romántico, individualismo, divinidad, perfectibilidad

La religión cristiana es uno de los elementos conformadores de la cultura europea. Hasta los inicios de la época ilustrada había sido la instancia legitimadora del mundo. A partir de entonces, sin embargo, la religión es cuestionada y sometida a un proceso de secularización en el que va a participar también la literatura romántica. A consecuencia del mismo, esta pasa a ser objeto de reflexión literaria y filosófica, más allá de los ámbitos de la fe y la teología que le eran propios. En su conocida introducción al Romanticismo, Gerhard Schulz subraya del siguiente modo la importancia de la religión en el pensamiento de esta corriente: "Romantik ist mit Religion ursächlich verbunden, denn die Vorstellung von einer romantischen Kultur entstand durch den Bezug der modernen europäischen Kultur auf das Christentum"1. En la literatura romántica se desarrolla un fenómeno estético y reflexivo por el cual la religión se 'romantiza'? . Este aspecto no se manifiesta solamente en las obras literarias y teóricas de las figuras más conocidas de la época, sino también en los textos de escritoras como Karoline von Günderrode (1780-1806), cuyo trabajo no ha tenido la misma repercusión que el de sus contemporáneos. Pese a ello, la obra de esta autora sólo puede ser leída como la de una verdadera representante de su tiempo.

En los primeros textos del Romanticismo se observa el afán de recuperación y re-definición de la esfera religiosa de la existencia humana. Este interés supone una reacción frente a la visión del mundo arraigada en el racionalismo extremo y el pensamiento materialista de la época, que cuestionaban la importancia de la religión, y frente a las limitaciones impuestas por el orden burgués. La necesidad de promover una dimensión religiosa individual, fomentada por estos autores, se contrapone a la consideración de la religión desde el punto de vista ilustrado como un mero instrumento social, sin mayor repercusión y utilidad para los verdaderos ejes en

\footnotetext{
${ }^{1}$ ScHULZ, Gerhard, Romantik: Geschichte und Begriff, München, C.H. Beck, 2008,

pág. 93.
2 Schulz utiliza el término "romantisieren" para definir el proceso por el cuál la religión es integrada en la poética romántica y pensada como fenómeno estético. Ibidem, pág. 94.

Futhark 7 (2012)

Bascoy, La dimensión religiosa, 9-42
}

ISSN 1886-9300 
torno a los que se debería definir la existencia humana: la ciencia y la razón. El volumen de discursos Über die Religion. Reden an die Gebildeten unter ihren Verächtern $(1799)^{3}$ de Friedrich D. E. Schleiermacher (1768-1834) es una de las primeras obras teóricas que se ocupan de esta problemática y que influyó de modo decisivo en el pensamiento romántico. El autor trata de definir los fundamentos del fenómeno religioso y de presentar el verdadero y originario sentido de la religión. Aunque para Schleiermacher no es posible expresar con palabras el sentimiento religioso, puesto que en el lenguaje se pierde su esencial inmediatez, considera imprescindible la manifestación y difusión de la religión para lograr recuperarla en su sentido primigenio. Este propósito es trasladado por los autores románticos al ámbito de la literatura, quienes creen en la posibilidad de mediar entre el lector y la divinidad y de comunicar así la religión a través de la poesía.

Karoline von Günderrode comparte con algunos de sus contemporáneos, como por ejemplo Friedrich Schlegel (1772-1829) o Novalis (1772-1801), la idea de que la poesía está intrínsecamente ligada a la religión. En 1805 fue publicado en la antología Herbsttage, editada por Sophie von La Roche, su relato "Geschichte eines Braminen", bajo el pseudónimo de Tian ${ }^{4}$. En este texto, la autora presenta el proceso de desarrollo individual y de conformación de la identidad de su protagonista, situando la dimensión religiosa en primer plano. La obra literaria sirve en este caso al propósito de acercar al lector la verdadera esencia de la religión. Pero no sería posible profundizar en las ideas vertidas en el relato, sin tener en cuenta el pensamiento romántico y, en especial, los discursos de Schleiermacher. Como se observa en la edición de sus estudios ${ }^{5}$, las anotaciones de Günderrode sobre sus lecturas dan testimonio de su interés por las ideas del filósofo. Con este

\footnotetext{
${ }^{3}$ SCHLEIERMACHER, Friedrich, Über die Religion: Reden an die Gebildeten unter ihren Verächtern, Berlin, New York, De Gruyter, 2001. Como breve introducción a la biografía de Schleiermacher, así como a la estructura y análisis de esta obra puede indicarse el siguiente artículo: BARTH, Ulrich, "Schleiermachers Reden als religionstheoretisches Modernisierungsprogramm", en: VIETTA, Silvio; KEMPER, Dirk (eds.), Ästhetische Moderne in Europa. Grundzüge und Problemzusammenhänge seit der Romantik, München, Fink, 1997, págs. 441-474.

${ }^{4}$ WESTPHAL, Wolfgang, Karoline von Günderrode und "Naturdenken um 1800", Essen: Die Blaue Eule, 1993, pág. 135.

${ }^{5}$ GüNDERRODE, Karoline von, Sämtliche Werke und ausgewählte Studien, I/ Varianten und Ausgewählte Studien, ed. Walter Morgenthaler, Basel, Stroemfeld/Roter Stern, 1991, págs. 282-287.

Futhark 7 (2012)

Bascoy, La dimensión religiosa, 9-42
}

ISSN 1886-9300 
trabajo se pretende indagar en la importancia de las teorías de Schleiermacher para la conformación del concepto de religión de la autora, en base al análisis de su relato "Geschichte eines Braminen", y mostrar, al mismo tiempo, la afinidad e integración de su obra en la corriente de pensamiento y literaria romántica.

\section{El concepto de religión de Friedrich Schleiermacher en el discurso "Über das Wesen der Religion"}

Schleiermacher comienza el primero de sus discursos, titulado "Apologie", disculpándose por la elección de un tema que a muy pocos interesa y que, en el momento histórico en el que escribe, permanece completamente descuidado ${ }^{6}$. El autor se expresa en actitud de reproche hacia la sociedad en general por el rechazo de la religión, pero especialmente hacia los intelectuales del momento. Considera que los ilustrados no alcanzan a comprender el verdadero sentido de la religión y que, a pesar de toda su sabiduría, menosprecian la dimensión religiosa del ser humano, que él cree esencial. La percepción que la mayor parte de los individuos tiene de la religión es solamente la del ropaje externo, es decir, las manifestaciones del culto en las religiones tradicionales, que envuelven y ocultan la verdadera experiencia religiosa. Con el paso del tiempo, la religión ha ido perdiendo su sentido originario y ha dejado de ocupar el lugar que le correspondería en la vida del ser humano. La participación en la vida religiosa ha venido determinada pues, casi siempre, por la tradición y las convenciones sociales, sin haber tras todo ello un verdadero sentimiento religioso. Schleiermacher afirma además que su época, en especial, está marcada por la incapacidad para observar la religión en su verdadera esencia, puesto que para sus contemporáneos lo más importante son "Menschheit und Vaterland, Kunst und Wissenschaft" y se han olvidado de la necesidad de lo eterno ${ }^{7}$. Tal y como ha señalado Kurt Nowak, Schleiermacher presenta en sus discursos una doble crítica $^{8}$. Por una parte, se muestra de acuerdo con los intelectuales ilustrados cuando rechazan la vacuidad y la carencia de sentido de las instituciones religiosas, de los dogmas y el culto. Sin

\footnotetext{
${ }^{6}$ SCHLEIERMACHER, pág. 57.

${ }^{7}$ Ibidem, págs. 57-58.

${ }^{8}$ NOWAK, Kurt, Schleiermacher und die Frühromantik. Eine literaturgeschichtliche Studie zum romantischen Religionsverständnis und Menschenbild am Ende des 18. Jahrhunderts in Deutschland, Göttingen, Vandenhoeck \& Ruprecht, 1986.

Futhark 7 (2012)

Bascoy, La dimensión religiosa, 9-42
}

ISSN 1886-9300 
embargo no acepta su aproximación al fenómeno religioso como ámbito de conocimiento -"sei es als dogmatisches Lehrsystem oder als philosophisch vermittelte Reflexion"9. La religión es para Schleiermacher una esfera de la existencia humana a la que no se puede tener acceso por medio de la razón.

La finalidad de los discursos de Schleiermacher consiste, por tanto, en explicar cuál es el verdadero sentido de la religión, tratando de despojar su esencia de los prejuicios y falsas ideas sobre la misma, basados en los signos externos de las manifestaciones religiosas. La (re)definición del concepto de religión es el objetivo principal del segundo discurso, que lleva por título "Über das Wesen der Religion"10, y que sirve de marco teórico para el posterior análisis del texto "Geschichte eines Braminen" de Karoline von Günderrode.

Para despojar la religión de los significados que no pertenecen a su sentido originario, pero que se le han ido atribuyendo con el paso del tiempo, Schleiermacher se centra en primer lugar en la diferenciación entre esta y los ámbitos de conocimiento de la metafísica y la moral. El autor muestra especial interés en aclarar la confusión generada por el hecho de que tanto la religión como la metafísica y la moral se ocupan del mismo objeto: el universo y la relación del ser humano con el mismo. Cada una de ellas, sin embargo, se aproxima a este objeto de modo diferente y tiene distinta finalidad. Mientras que la metafísica es filosofía especulativa y su interés se centra en conocer el origen del universo, sus fundamentos y sus leyes, la moral se ocupa del comportamiento y del código normativo que lo regula. El objetivo de la metafísica es hallar una instancia que legitime el universo y la categorización de los elementos que lo componen. Dicha instancia sería, según Schleiermacher, un ser primigenio que, además de dar validez al orden universal, estableciese al mismo tiempo las leyes y normas morales que lo rigen. Al contrario de estos dos ámbitos, la religión no se ocupa del universo ni desde la perspectiva de la reflexión ni desde la del comportamiento ${ }^{11}$. La cuestión fundamental en la

\footnotetext{
${ }^{9}$ NOWAK, pág. 151.

${ }^{10}$ SCHLEIERMACHER, págs. 74-115.

${ }^{11}$ Ibidem, pág. 79. Hermann Timm acentúa en su estudio la relevancia y la novedad de las teorías de la religión de Schleiermacher, centrándose en el distanciamiento del autor del discurso teológico tradicional: "Seit der antiken Philosophie war Religion als Gotteserkenntnis und -verehrung definiert worden. Schleiermacher zuerst hat sie von diesem metaphysischen Erkenntnisanspruch des Theismus - aus Offenbarung oder Vernunft - gelöst. Die Theologie wurde als logisch sekundär eingestuft. [...] Ist die Futhark 7 (2012) Bascoy, La dimensión religiosa, 9-42 ISSN 1886-9300
} 
religión es el principio unificador que aúna todo lo individual -todos los seres únicos que componen el mundo- y que los transforma en una totalidad. El universo es definido desde el punto de vista de la religión como la unidad de todos los seres que lo conforman y que participan en su desarrollo continuo ${ }^{12}$.

La metafísica y la moral se acercan al universo desde una perspectiva antropocéntrica. Esta característica no es propia, sin embargo, de la religión y constituye una diferencia fundamental entre la dimensión religiosa de la existencia y los ámbitos de la razón y del comportamiento. En "Über das Wesen der Religion", Schleiermacher critica la visión del mundo que sustenta el orden social de su tiempo, en la que el individuo se sitúa en el centro de la realidad y establece como su objetivo el dominio del entorno. La concepción antropocéntrica limita las posibilidades de la existencia humana, en tanto que solo admite como válidas determinadas formas de entender la realidad. Para ejemplificar esta idea, Schleiermacher introduce en su argumentación la figura mitológica de Prometeo ${ }^{13}$, quien había robado el fuego a los dioses para entregárselo a los humanos -el fuego simboliza el sentimiento de infinitud y de semejanza a la divinidad del ser humano. Pero este acto delictivo de Prometeo no habría sido necesario si la humanidad poseyese lo que el autor denomina "Sinn und Geschmack fürs Unendliche", es decir,

Religion »weder Denken noch Handeln«, so bestreitet sie außer dem Primat des kognitiven auch den des normativen Verifikationsvermögens. Denn inn anerkennen hieße doch nur den Rationalismus variieren zu einer zweckrationalen Erklärung des Phänomens." TıMm, Hermann, Die heilige Revolution. Das religiöse Totalitätskonzept der Frühromantik. Schleiermacher - Novalis - Friedrich Schlegel, Frankfurt am Main, Syndikat, 1987, págs. 31-32.

${ }^{12}$ En su análisis acerca de los significados del universo en los discursos, Nowak ha demostrado que Schleiermacher es el primer autor que introduce este término como un concepto específico del ámbito de la religión. NowAK, pág. 167.

${ }_{13}$ SCHLEIERMACHER, pág. 80. La figura mitológica de Prometeo no aparece en el pensamiento romántico como un símbolo positivo, sino, como indica Sabine Schormann, como "Prototyp des nie zum Ziel kommenden rationalistischen Perfektionsstrebens, als Vertreter einer der Arbeit huldigenden Moral, als Begründer eines rein in der Diesseitigkeit verhafteten Wissenschaftsdenkens". SCHORMANN, Sabine, Bettine von Arnim: die Bedeutung Schleiermachers für ihr Leben und Werk, Tübingen, Niemeyer, 1993. Aquí pág. 128. Si para los ilustrados Prometeo representa la idea del individuo creativo y activo, los románticos lo identifican con la figura del filisteo. Esta limitación puede ser superada, según el pensamiento romántico, gracias a la religión.

Futhark 7 (2012)

Bascoy, La dimensión religiosa, 9-42

ISSN 1886-9300 
una cualidad innata del individuo que le capacita para percibir la unidad del universo o, lo que es lo mismo, para la religión ${ }^{14}$.

Si la metafísica y la moral, como se ha indicado, fomentan una visión antropocéntrica de la realidad, sustentada en la oposición entre el ser humano y el mundo, la religión, al contrario, concibe al individuo como una pieza más del universo. De este modo, la persona, como elemento individual y finito, al igual que todos los demás elementos que componen el universo, es una expresión de la infinitud del mismo. Para explicar esta relación, Schleiermacher utiliza en sus discursos los pares terminológicos 'lo finito'/lo infinito' y 'lo individual'/'la totalidad'. En contraposición a la totalidad, que es infinita e ilimitada, sus elementos son finitos y limitados, siendo cada ser individual a su vez reflejo de la infinitud del todo. Para afianzar esta idea, Schleiermacher se remite a las teorías de Espinoza, por quien el autor demuestra una gran admiración ${ }^{15}$. De él toma el postulado 'Alles in Einem', sobre el que Schleiermacher construye su concepto de religión, lo que queda claramente reflejado en la idea del ser humano como parte de la totalidad del mundo.

La vivencia religiosa es la experiencia de la infinitud del universo. Frente a la metafísica y a la moral, que se aproximan a la realidad desde la reflexión y la actuación respectivamente, la experiencia religiosa consiste en lo que el autor denomina 'Anschauung' -contemplación-y 'Gefühl' -sentimiento ${ }^{16}$. Esta forma de captar el universo no obedece ni a la razón ni a las normas morales, sino que se trata del resultado de un acto contemplativo. El autor se refiere con el concepto de contemplación a un proceso similar al de la percepción sensorial, en el cuál se observan dos momentos complementarios: el estímulo externo y la percepción. Antes de que nuestra conciencia se percate de los objetos que nos rodean, es necesario que los órganos sensoriales sean estimulados por estos. De este modo, los objetos externos son los que ejercen en primer lugar su influencia sobre el individuo que los contempla: "Alles Anschauen gehet aus von einem Einfluß des Angeschaueten auf den Anschauenden, von einem ursprünglichen und unabhängigen Handeln des ersteren, welches dann von dem letzeren seiner Natur

\footnotetext{
${ }^{14}$ SCHLEIERMACHER, pág. 80.

${ }^{15}$ Ibidem, pág. 81.

${ }^{16}$ Ibidem, pág. 79.

Futhark 7 (2012)
}

ISSN 1886-9300 
gemäß aufgenommen, zusammengefaßt und begriffen wird"17. Lo que el ser humano percibe de la realidad no son los objetos en sí mismos, sino la actuación continua de estos sobre el individuo y, dado que dichos objetos son también representaciones del universo, el autor concibe el estímulo que ejercen sobre el ser humano como una manifestación directa de lo infinito. La contemplación religiosa no es, por tanto, un acto de conocimiento sino el resultado de la percepción directa del universo, tratándose de un momento inconsciente 0 instintivo y no de una experiencia intelectual 0 reflexiva. En el segundo paso de la experiencia religiosa se produce una transformación en el espíritu, causada por el estímulo de los objetos externos. Lo que permanece de la influencia del entorno es el sentimiento de unidad del universo ${ }^{18}$. Según el análisis de Kurt Nowak, el concepto de contemplación de Schleiermacher hace referencia a un momento centrado en el objeto, mientras que el sentimiento, como resultado de esta, afecta al sujeto ${ }^{19}$. Por este motivo, la experiencia de lo infinito es un acto individual y subjetivo, cuyo resultado, la percepción religiosa, es específico del ser humano individua $\left.\right|^{20}$. En este sentido, Schleiermacher defiende la idea de la religión individual de cada ser humano. Así, la intensidad de los sentimientos religiosos individuales determina el grado de

\footnotetext{
17 Ibidem, págs. 81-82. Tal y como Schleiermacher lo describe, el entorno o la naturaleza no es pasiva sino activa, puesto que es su función estimular al individuo. De este modo, lo que los seres humanos perciben sería el efecto de la actuación de la naturaleza sobre ellos. Ya que esta acción es continuada, el universo se revela a cada instante a través de la naturaleza.

${ }^{18}$ Como ha señalado Ernst Müller, en el momento de la percepción religiosa se produce una identificación del sujeto con el objeto de la contemplación, experimentándose un sentimiento de pertenencia al universo. Sabine Schormann ha tratado de enmarcar el concepto de 'sentimiento' de Schleiermacher en la discusión teórica idealista de la época, entendiendo la idea de acercamiento a lo absoluto -o concepto de perfectibilidad- como un fenómeno religioso. La percepción religiosa es para la autora una forma prerreflexiva de conciencia individual: se trata del sentimiento de la dependencia del individuo con respecto a la unidad del universo. Es a través de este sentimiento cómo el ser humano descubre la razón transcendente de su existencia y, por tanto, su verdadera identidad, lo que hace que no sea posible la comprensión de la misma sin la religión. MüLLER, Ernst, "Religion als 'Kunst ohne Kunstwerk'. F.D.E. Schleiermachers Reden 'Über die Religion' und das Problem ästhetischer Subjektivität", en BRAUNGART, Wolfgang; FuCHS, Gotthart; KOCH, Manfred (eds.), Ästhetische und religiöse Erfahrungen der Jahrhundertwenden. 1. Um 1800, Paderborn, Schöningh 1997, págs. 149-165; SCHORMANN, pág. 148.

${ }^{19}$ NowaK, pág. 169.

${ }^{20}$ En "Über das Wesen der Religion”, Schleiermacher utiliza el término 'Anschauung' tanto para referirse al primer momento de la contemplación como a la percepción religiosa: la síntesis de la contemplación y el sentimiento.
}

Futhark 7 (2012)

Bascoy, La dimensión religiosa, 9-42

ISSN 1886-9300 
religiosidad de cada persona: "So wie die besondere Art wie das Universum sich Euch in Euren Anschauungen darstellt, das Eigenthümliche Eurer individuellen Religion ausmacht, so bestimmt die Stärke dieser Gefühle den Grad der Religiosität”21.

Schleiermacher reconoce a la naturaleza, como elemento externo objeto de la contemplación humana, una función relevante. Pero, mientras que el pensamiento romántico en general le otorga un papel más activo en su interactuación con el ser humano, en las teorías de Schleiermacher prevalece el momento subjetivo de la experiencia religiosa: "Zur äußeren Natur, welche von so Vielen für den ersten und vornehmsten Tempel der Gottheit, für das innerste Heiligthum der Religion gehalten wird, führe ich Euch nur als zum äußersten Vorhof derselben"22. A pesar de restringir la función del entorno en el ámbito de la religión, el autor se muestra muy crítico tanto con la visión de la naturaleza como fuerza inconmensurable que hace temer a las personas, como con la idea del dominio e instrumentalización de la misma al servicio de ser humano, que se apoya en la concepción antropocéntrica y racionalista del mundo. Al igual que los autores románticos, Schleiermacher se opone a la jerarquización en la relación entre el ser humano y la naturaleza que le sitúa a él por encima del entorno, colocando ambos elementos de la realidad en una posición de igualdad como partes del universo. Cada una de las individualidades que componen la totalidad se encuentra en la misma relación con ella, del mismo modo que todos los elementos entre sí. En el acercamiento del individuo a su entorno, contemplar la naturaleza "mit Religion" 23 no significa para el autor la obtención de conocimiento sobre sus manifestaciones externas -sobre la belleza o las particularidades materiales de la misma-, sino sobre las leyes naturales que actúan en ella, percibiendo así la unidad divina y la inalterabilidad del mundo que subyacen a dichas leyes. Schleiermacher destaca la acción producida por la atracción -el amor-y la repulsión como las fuerzas primordiales de la naturaleza, que determinan las relaciones entre los objetos y que los obligan a encontrarse en constante movimiento. En este orden natural se reconoce entonces la obra del espíritu del mundo. Lo que el ser humano observa como aislado, individual o diferente es solo una apariencia, puesto que en la naturaleza todo se

\footnotetext{
${ }^{21}$ SCHLEIERMACHER, pág. 87.

22 Ibidem, pág. 91.

${ }^{23}$ Ibidem, pág. 93.

Futhark 7 (2012)
}

ISSN 1886-9300

Bascoy, La dimensión religiosa, 9-42 
encuentra en constante cambio. La persona que ha percibido la acción del espíritu del mundo y la ha observado en todos los seres, ha tenido una percepción religiosa. Dicha percepción no se produce por la mera contemplación del entorno, sino que es imposible, según Schleiermacher, percibir la actuación del espíritu del mundo si el individuo no ha descubierto antes en su propio interior las mismas leyes que ordenan la naturaleza: "Darum ist es auch das Gemüth eigentlich worauf die Religion hinsieht, und woher sie Anschauungen der Welt nimmt; im innern Leben bildet sich das Universum ab, und nur durch das innere wird erst das äußere verständlich"24.

Para llegar a contemplar la unidad del universo en la naturaleza es imprescindible que el individuo haya descubierto antes la humanidad -entendida como lo esencial común a los seres humanos- en los demás. Schleiermacher afirma que el individuo aislado no estaría capacitado para la religión, puesto que "um die Welt anzuschauen und um Religion zu haben, muß der Mensch erst die Menschheit gefunden haben, und er findet sie nur in Liebe und durch Liebe" ${ }^{\prime 25}$. El principio del amor, al igual que en el pensamiento romántico, tendrá en la concepción de la religión de Schleiermacher una función primordial como fuerza unificadora. Para ilustrar la idea expuesta en la anterior cita, el autor presenta la historia del primer hombre que habitó el paraíso. Aunque dios se manifestaba de muchas formas al hombre, este no era capaz de comprenderle ni de responderle, hasta que dios comprobó que no debía estar solo y le concedió una compañera ${ }^{26}$. Solo gracias al descubrimiento de su propia naturaleza humana en la mujer, por medio del amor, es como el primer hombre pudo descubrir la humanidad y entender así el mundo. En su análisis de los discursos de Schleiermacher, Gunter Wenz llama la atención sobre el proceso de autodeterminación del ser humano -un proceso religioso, en este caso-, que tiene lugar no de forma deductiva y monológica, sino dialógica, a través de la identificación con otro ser humano ${ }^{27}$. En el interior del propio ser se encuentra, según Schleiermacher, un "Compendium der

\footnotetext{
${ }^{24}$ Ibidem, pág. 95. Sobre la concepción de la naturaleza en Schleiermacher véase también NoWAK, pág. 227.

${ }_{25}$ Ibidem, pág. 96.

${ }^{26}$ Ibidem, pág. 96.

${ }^{27}$ WENZ, Gunther, "Sinn und Geschmack fürs Unendliche. F.D.E. Schleiermachers Reden über die Religion an die Gebildeten unter ihren Verächtern von 1799", en Bayerische Akademie der Wissenschaften, Sittzungsberichte, vol. 3, 1999, págs. 1-52. Futhark 7 (2012) Bascoy, La dimensión religiosa, 9-42 
Menschheit" ${ }^{28}$, de modo que el individuo encuentra en sí mismo y en los demás únicamente variaciones del mismo germen. El amor cumple en este sentido una función armonizadora y unificadora, que permite encontrar lo que es igual a uno mismo en los demás y tender así un puente entre los individuos ${ }^{29}$. Para Schleiermacher, el descubrimiento de la humanidad supone la primera fase de la religión. En esta parte del proceso es necesario que el individuo salga de sí mismo y, una vez haya reconocido en otros seres humanos su propia naturaleza, regrese después a su propia individualidad y descubra de nuevo la humanidad en su interior.

La tendencia general a observar los objetos del entorno en su individualidad, es decir, a desmenuzar el mundo, supone un obstáculo para el individuo a la hora de percibir la humanidad. Por este motivo es necesaria, según Schleiermacher, la figura del mediador para ayudarle a lograr esta percepción:
[...] sucht unter allen den heiligen Männern, in denen die Menschheit sich unmittelbar offenbart, einen auf, der der Mittler sein könne zwischen Euer eigeschränkten Denkungsart und den ewigen Grenzen der Welt; und wenn Ihr inn gefunden habt, dann durchlauft die ganze Menschheit und laßt alles was Euch bisher anders schien, von dem Widerschein dieses neuen Lichts erhellt werden ${ }^{30}$.

La actividad mediadora tiene una importancia esencial para Schleiermacher. Aunque la capacidad para la percepción religiosa es innata y el individuo ya posee en su interior el sentido para la religión, a menudo no puede descubrirla o activarla por sí mismo, sino solamente gracias a la ayuda de un mediador.

En los pasos de la religión descritos, el individuo sólo llega a alcanzar una percepción de la humanidad "in ihrem Sein"31, siendo precisa aún una percepción de la misma en su proceso evolutivo. Según Schleiermacher, en la actividad del espíritu del mundo impulsada por el principio de transformación- se refleja el desarrollo de la humanidad, que solo puede ser descubierto por medio de la contemplación del proceso histórico. La historia constituye de este

\footnotetext{
${ }^{28}$ SCHLEIERMACHER, pág. 100.

${ }^{29}$ En las teorías de Schleiermacher el amor tiene, según Kurt Nowak, como principio unificador y armonizador una función socializadora. Este principio es considerado como constitutivo de la humanidad. NowAK, pág. 184.

${ }^{30}$ SCHLEIERMACHER, págs. 99-100.

${ }^{31}$ Ibidem, pág. 100.

Futhark 7 (2012)

Bascoy, La dimensión religiosa, 9-42
}

ISSN 1886-9300 
modo el objeto más elevado de la religión: "Die verschiedenen Momente der Menschheit aneinander zu knüpfen, und aus ihrer Folge den Geist in dem das Ganze geleitet wird errathen, das ist ihr höchstes Geschäft" ${ }^{\prime 32}$. Lo infinito no es percibido únicamente en el presente de los objetos y de los individuos, sino sobre todo a través de la evolución del mundo desde sus orígenes hasta el futuro. La historia es concebida por Schleiermacher como progresión lineal, de modo que constituye una trayectoria de perfeccionamiento, a través de sus transformaciones internas, que conduce a la humanidad a lo más elevado. Las distintas épocas en el proceso evolutivo de la historia, cuya superación resulta de la acción del espíritu del mundo, son denominadas momentos. Cada nuevo momento es construido, en palabras de Schleiermacher, a partir de las ruinas de la época anterior $^{33}$, de forma que se produce una renovación. La evolución histórica, en tanto que conduce al perfeccionamiento, es positiva. Así pues, toda transformación, la destrucción y construcción del universo como obra del espíritu del mundo, junto con la ayuda del principio del amor, ofrecen al ser humano la posibilidad de reconocer la verdadera humanidad.

Las percepciones religiosas que surgen de la contemplación de la naturaleza, la humanidad y la historia son para Schleiermacher, en realidad, la condición para que se supere la primera fase de la experiencia religiosa, aunque está claro para el autor que no podrán ser alcanzadas por la mayoría de los individuos -a excepción de unos pocos- sin la ayuda de un mediador. Cuando el individuo no es capaz por sí mismo de tener las percepciones fundamentales, necesita, como se ha expuesto, el apoyo de una figura mediadora que, después de orientarle y de ayudarle a activar el sentido interno de la religión, ya no será necesaria, puesto que la percepción religiosa es totalmente individual y subjetiva. Cualquiera que haya superado la primera fase de la religión puede desempeñar esta función mediadora. Es decir, quienes hayan contemplado el mundo que les rodea y hayan regresado a sí mismos para descubrir en su propio interior el infinito, podrán ayudar a otros a tener percepciones religiosas. Ernst Müller indica en este sentido que el propio Schleiermacher realiza una función mediadora a través de sus textos, en tanto que como orador se ocupa en los discursos de manifestar sus propias experiencias religiosas y de transmitirlas a

\footnotetext{
32 Ibidem, pág. 100.

${ }^{33}$ Ibidem, pág. 101.

Futhark 7 (2012)

ISSN 1886-9300
}

Bascoy, La dimensión religiosa, 9-42 
sus lectores, tratando de este modo de despertar en ellos el sentido de la religión ${ }^{34}$.

La segunda fase de la religión es aún más difícil de alcanzar $y$, según Schleiermacher, solo muy pocas personas pueden superarla. El individuo debe mirar más allá de la percepción de la humanidad y buscar el infinito sobrepasando sus límites, ya que esta percepción representa solamente un nexo entre el individuo y la totalidad. La unión directa entre el ser humano y el universo no es reconocible todavía, sino que es necesario que el individuo encuentre en sí mismo un carácter más elevado, que le permita ver más lejos de la manifestación de la infinitud en lo finito. La segunda fase de la religión es descrita por Schleiermacher como el proceso de aspiración a lo más elevado, es decir, la unión plena de lo finito y lo infinito. Sólo la religión, que permite al individuo llegar a lo más elevado, le proporciona a éste universalidad. Para superar los límites de la finitud humana es, por tanto, imprescindible la esfera de la religión:

[...] das ist die einzige Art wie Ihr Euch bei einer schon gewählten Richtung des Gemüths auch das, was außer derselben liegt, aneignen könnt, nicht wiederum aus Wilkühr als Kunst, sondern aus Instinkt fürs Universum als Religion, und weil sie auch in der religiösen Form wieder rivalisieren, so erscheint auch die Religion öfter vereinzelt als Naturpoesie, Naturphilosophie oder Naturmoral, als in ihrer ganzen Gestalt vollendet und alles vereinigend. So sezt der Mensch dem Endlichen, wozu seine Willkühr inn hintreibt ein Unendliches, dem zusammenziehenden Streben nach etwas Bestimmten und Vollendetem das erweiternde Schweben im Unbestimmten und Unerschöpflichen an die Seite; so schaft er seiner überflüßigen Kraft einen unendlichen Ausweg, und stellt das Gleichgewicht und die Harmonie seines Wesens wieder her, welche unwiderbringlich verloren geht, wenn er sich, ohne zugleich Religion zu haben, einer einzelnen Direktion überläßt ${ }^{35}$.

El ser humano necesita la dimensión religiosa para que su existencia adquiera verdadero sentido y pueda realizarse así plenamente. Puesto que son las instancias sociales las que regulan la vida diaria del individuo, es preciso el contrapeso de la religión para que este pueda desarrollar su verdadera identidad. Es por ello

\footnotetext{
${ }^{34}$ MÜLLER, pág. 149.

${ }^{35}$ SCHLEIERMACHER, pág. 107.

Futhark 7 (2012)
}

Bascoy, La dimensión religiosa, 9-42

ISSN 1886-9300 
que la religión debe estar presente en la actuación del ser humano, pero no como una norma a seguir, sino como forma de ver el mundo, de modo que "die religiösen Gefühle [...] wie eine heilige Musik alles Tun des Menschen begleiten; er soll alles mit Religion tun, nichts aus Religion" ${ }^{36}$. Es gracias a esta manera de captar el universo que el ser humano puede encontrar armonía en su existencia y también universalidad, ambos objetivos del perfeccionamiento individual según Schleiermacher. Así pues, el individuo puede dar a su vida la orientación correcta, cuyo verdadero sentido no se encuentra en el orden social sino en las leyes eternas que proceden del interior del ser humano. Schleiermacher exhorta entonces a sus lectores, por su propio bien, a recuperar la dimensión religiosa de la existencia y a regresar al origen del ser humano ${ }^{37}$.

Otro de los temas que el autor trata en el segundo discurso es la necesidad de diferenciar claramente el verdadero sentido de la religión de lo que representan para la sociedad las instituciones religiosas en su época, que forman parte de su entramado y que sirven a los propósitos del orden filisteo ${ }^{38}$. Las religiones tradicionales e institucionalizadas merecen la crítica del autor, entre otros motivos, por apoyarse en dogmas y doctrinas que no son más que productos abstractos fruto de la reflexión humana y, por lo tanto, algo secundario y no verdadera religión. El autor considera dichos dogmas y doctrinas como la expresión de percepciones religiosas concretas o como el resultado de reflexionar acerca de la función de la religión. Puesto que la percepción religiosa no deriva de un proceso racional de conocimiento, sino que es una percepción inmediata del universo, los contenidos de las religiones tradicionales no pueden considerarse como religión en sí misma. Otra particularidad de las religiones como instituciones sociales es su apoyo en elementos como los milagros, la inspiración, revelaciones o experiencias sobrenaturales, que tampoco pertenecen al ámbito de la verdadera experiencia religiosa. Schleiermacher critica además la jerarquía eclesiástica como estructura de poder, orientada a las necesidades de la sociedad y contraria al sentido de una verdadera

\footnotetext{
${ }^{36}$ Ibidem, pág. 87.

${ }^{37}$ Ibidem, pág. 110.

38 En los discursos, tal y como se ha afirmado en diversos estudios, a pesar del esfuerzo de Schleiermacher por diferenciar el ámbito religioso, subjetivo, de otros ámbitos de la vida humana, se observa que la religión tiene repercusión directa sobre la vida práctica del individuo. Aun así el autor lleva a cabo una importante tarea de desfuncionalización, despolitización y desinstitucionalización de la religión.

Futhark 7 (2012)

Bascoy, La dimensión religiosa, 9-42
}

ISSN 1886-9300 
comunidad religiosa. La iglesia se erige fundamentalmente como institución moral, preocupada por determinar y dirigir la vida de sus miembros. Mientras que esta actúa como instancia externa que regula la existencia del individuo, el autor aboga por el regreso a los orígenes de la religión en el interior del ser humano y por la experiencia religiosa individual:

\begin{abstract}
Ja, wer nicht eigne Wunder sieht auf seinem Standpunkt zur Betrachtung der Welt, in weßen Innern nicht eigene Offenbarungen aufsteigen, wenn seine Seele sich sehnt die Schönheit der Welt einzusaugen, und von ihrem Geiste durchdrungen zu werden; wer nicht hie und da mit der lebendigsten Überzeugung fühlt, daß ein göttlicher Geist inn treibt und $d a ß$ er aus heiliger Eingebung redet und handelt; wer sich nicht wenigstens - denn dies ist in der That der geringste Grad - seiner Gefühle als unmittelbarer Einwirkungen des Universums bewußt ist, und etwas eigenes in ihnen kennt was nicht nachgebildet sein kann, sondern ihren reinen Ursprung aus seinem Innersten verbürgt, der hat keine Religion. Glauben, was man gemeinhin so nennt, annehmen was ein anderer gethan hat, nachdenken und nachühlen wollen was ein Anderer gedacht und gefühlt hat, ist ein harter und unwürdiger Dienst, und statt das höchste in der Religion zu sein, wie man wähnt, muß er grade abgelegt werden, von Jedem der in ihr Heiligthum dringen will. Ihn haben und behalten wollen, beweiset daß man der Religion unfähig ist; inn von andern fordern, zeigt daß man sie nicht versteht ${ }^{39}$.
\end{abstract}

La religión no puede tomarse prestada de otros ya que solo se vivencia individual y subjetivamente, si bien en ocasiones puede ser necesaria la ayuda puntual de un mediador. Por este motivo, Schleiermacher critica la fe como una forma de religiosidad 'prestada'. Ni la fe en la religión de otro ni la fe en escrituras sagradas pueden considerarse como el fundamento de la religión individual. Estos textos son para Schleiermacher únicamente la manifestación de una percepción religiosa originaria que, por tratarse de una forma de expresión verbal de la misma, han perdido la inmediatez de la experiencia religiosa individual.

En la última parte del discurso "Über das Wesen der Religion", el autor se ocupa de los conceptos de dios y de la eternidad, que tienen un papel fundamental en las religiones

\footnotetext{
${ }^{39}$ SCHLEIERMACHER, pág. 109.
}

Futhark 7 (2012)

Bascoy, La dimensión religiosa, 9-42

ISSN 1886-9300 
tradicionales. En el contexto de la verdadera religión defendida por Schleiermacher, sin embargo, su importancia es secundaria y no constituyen en absoluto el núcleo de la misma, sino que lo esencial en ella es la percepción del universo. Tanto dios como la eternidad son sólo ideas concretas que se corresponden con determinadas percepciones religiosas. De esta forma, en función de cómo el individuo se aproxime a la unidad del universo, pueden originarse diversas representaciones de la deidad, que el autor asigna a tres estadios diferenciados del desarrollo histórico de la humanidad. En el primero de ellos, el universo es contemplado como un caos confuso, de modo que el individuo tiene solamente una ligera intuición de su unidad. En este estadio aparece un tipo de divinidad que se corresponde con la figura de un ídolo o fetiche, al que no se le atribuyen cualidades determinadas. En el siguiente estadio, el universo es percibido como una multiplicidad de manifestaciones, carente aún de unidad, a cuya percepción corresponderán diversas divinidades que poseen cualidades específicas y que desempeñan funciones diferenciadas. Y, finalmente, es en el tercer estadio en el que el autor sitúa la verdadera experiencia del universo: la percepción de la totalidad como unidad en la multiplicidad. Las percepciones que el individuo experimenta en este nivel se ajustan así a la fórmula de Espinoza 'Eins und Alles' y a estas les corresponde la idea de un dios único. A medida que la humanidad avanza en los estadios descritos, Schleiermacher encuentra en el ser humano un sentido para el universo más desarrollado. Por este motivo, el autor considera que debe concedérsele a Espinoza el grado más elevado de religiosidad. Una vez alcanzada la percepción de la unidad del universo que, como se ha expuesto, es lo esencial de la religión para Schleiermacher, la necesidad de un dios que se corresponda con la misma depende de la fantasía humana:

In der Religion wird das Universum angeschaut, es wird gesetzt als ursprünglich handelnd auf den Menschen. Hängt nun Eure Fantasie an dem Bewußtsein Eurer Freiheit so daß sie es nicht überwinden kann dasjenige was sie als ursprünglich wirkend denken soll anders als in der Form eines freien Wesens zu denken; wohl, so wird sie den Geist des Universums personifizieren und Ihr werdet einen Gott haben; hängt sie am Verstande, so daß es Euch immer klar vor Augen steht, Freiheit habe nur Sinn im Einzelnen und fürs Einzelne; wohl, so werdet $\mathrm{Ihr}$ eine Welt haben und keinen Gott. Ihr, hoffe ich, werdet es für keine Lästerung halten, daß Glaube an Gott abhängt von der Richtung der Fantasie; Ihr 
werdet wißen daß Fantasie das höchste und ursprünglichste ist im Menschen, und außer ihr alles nur Reflexion über sie; Ihr werdet es wißen daß Eure Fantasie es ist, welche für Euch die Welt erschaft, und daß Ihr keinen Gott haben könnt ohne Welt $^{40}$.

Schleiermacher explica en este fragmento cómo la idea de dios está supeditada a la existencia y contemplación del entorno, es decir, del universo y, por tanto, cómo es imposible que el ser humano pueda tener una imagen de la deidad sin el mismo. La forma en la que el ser humano contempla el mundo y su propia posición dentro de él determina la necesidad o no de los dioses. Si bien la idea de dios no supone un problema para Schleiermacher, el autor trata de subrayar su origen para que el lector comprenda que es posible tener religión prescindiendo de la imagen de una divinidad. Del mismo modo que esta es un producto secundario de la religión, es decir, la mera expresión de una percepción religiosa, también el concepto tradicional de eternidad es criticado por el autor. Puesto que la finalidad de la religión es percibir la unidad del universo, la insistencia del ser humano en su individualidad y en la sociedad humana, que son finitos, se oponen a su verdadero objetivo que consiste en que el individuo se contemple a sí mismo como parte de lo infinito, superando las limitaciones de la humanidad -proceso que se da por culminado tras la muerte. Según Schleiermacher, la religión confiere eternidad al ser humano en tanto que este va poco a poco reprimiendo su existencia individual: "Mitten in der Endlichkeit Eins werden mit dem Unendlichen und ewig sein in einem Augenblick, das ist die Unsterblichkeit der Religion” ${ }^{\prime 1}$.

\section{La dimensión religiosa individual en "Geschichte eines Braminen"}

De los diferentes trabajos publicados hasta la actualidad sobre la obra de Karoline von Günderrode, son pocos los que ofrecen un análisis del texto "Geschichte eines Braminen". Entre ellos cabe señalar el capítulo que le dedica Wolfgang Westphal ${ }^{42}$, en el que además de aportar su propia interpretación del texto, revisa las ideas expuestas anteriormente por otros autores. A pesar de

\footnotetext{
${ }^{40}$ Ibidem, pág. 113.

${ }^{41}$ Ibidem, pág. 115.

${ }^{42}$ WESTPHAL, págs. 135-145.

Futhark 7 (2012)
}

ISSN 1886-9300

Bascoy, La dimensión religiosa, 9-42 
admitir la relevancia de los discursos de Schleiermacher, la principal intención de Westphal es la de estudiar la recepción por parte de la autora de la cultura india y de los mitos orientales, sin llegar a profundizar en el concepto de religión afín al del filósofo. En un estudio más reciente, Ruth Christmann ${ }^{43}$ se ocupa de forma breve de la importancia de Schleiermacher en la trayectoria literaria de Günderrode. En su revisión del relato se remite a la aportación de Westphal, destacando ante todo el desarrollo de la vita contemplativa por parte del protagonista ${ }^{44}$. Christmann sólo hace referencia a Schleiermacher cuando se reflejan en el texto las teorías del filósofo que la propia escritora recoge en las anotaciones de sus lecturas. Es preciso, por tanto, un análisis más exhaustivo en el que se tenga en cuenta la esencial influencia de la concepción religiosa de Schleiermacher.

En el relato "Geschichte eines Braminen", Günderrode se sirve del proceso de desarrollo individual del protagonista para ilustrar las relaciones del ser humano con la naturaleza, la sociedad y la deidad. La explicación del comportamiento del individuo en la esfera de lo divino y el concepto de religión constituyen el tema principal del texto. Al igual que otros autores del Romanticismo, la escritora otorga a la dimensión religiosa una importancia fundamental, coincidiendo así en su defensa de la esfera metafísica con el objetivo de Schleiermacher en su discurso sobre la esencia del fenómeno religioso.

El texto consiste en la narración por parte del brahmán Almor de su historia vital. Sus palabras están dirigidas a $\operatorname{Lubar}^{45}$, que le escucha como a un maestro. El protagonista va describiendo entonces las diferentes etapas de su desarrollo como individuo, desde la infancia hasta el momento en el que decide asentarse finalmente en la India. Procedente de Esmirna, Almor es hijo de un rico comerciante francés que había abandonado la religión cristiana y se había convertido al islamismo. A la edad de dieciséis años, el padre le envía a vivir a una gran ciudad europea para que aprenda el oficio de comerciante. Durante su estancia allí, las únicas

\footnotetext{
43 CHRISTMANN, Ruth, Zwischen Identitätsgewinn und Bewußtseinsverlust. Das philosophisch-literarische Werk der Karoline von Günderrode (1780-1806), Frankfurt am Main, Peter Lang, 2005.

45 Aunque el texto está concebido como un diálogo, el relato se compone fundamentalmente de la narración de Almor e incluye una única intervención de Lubar.

Futhark 7 (2012)

Bascoy, La dimensión religiosa, 9-42
}

ISSN 1886-9300 
preocupaciones del joven son el placer del divertimento y el disfrute de los bienes materiales, hasta que, a raíz de dos acontecimientos importantes, se despierta su conciencia moral. La muerte de su padre y la ruina del comerciante con el que trabaja como aprendiz son las experiencias negativas que le llevan a reflexionar sobre el sentido de su existencia, dando comienzo así a un proceso de desarrollo espiritual. La evolución de Almor se produce en dos fases que se corresponden, respectivamente, con el descubrimiento de la humanidad y el de la deidad.

Aunque el primer acercamiento del espíritu al entorno debe producirse ya a una edad temprana, la infancia del protagonista transcurre, sin embargo, ajena al mundo que le rodea. De sus primeros años recuerda especialmente la relación infeliz con su padre ${ }^{46}$. Almor se lamenta del incumplimiento por parte de la figura paterna de su principal función como educador, pues son los padres quienes, según él, deben facilitar a los hijos el contacto tanto con la naturaleza como con la sociedad. En esta tarea es esencial el amor de los padres: "Durch die Eltern spricht die Natur zu den Kindern. Wehe den armen Geschöpfen, wenn diese erste Sprache kalt und lieblos ist!" ${ }^{\prime 7}$. Günderrode subraya de este modo la función de los progenitores como mediadores entre los niños y el mundo, tanto en la vertiente de los instintos y los afectos como en la vertiente social y moral, siendo especialmente relevante su papel a partir del momento en el que los hijos comienzan a percibir el entorno de forma espiritual, es decir, "mit den Augen ihres Geistes"48.

Puesto que Almor se encontraba solo ante el mundo, sin el apoyo y el amor de sus padres, permanecía indiferente a él, sin la necesidad de hacerse preguntas sobre la vida y sobre el orden social. Tampoco la religión suscitaba en el protagonista ningún interés $y$, a pesar de que participaba con su padre en las ceremonias del culto mahometano, lo hacía sólo como un espectador ajeno, sin preocuparse en comprender su sentido. Almor aceptaba simplemente la opinión que su padre sostenía sobre el fenómeno religioso, sin cuestionarla: "Mein Vater hatte oft gesagt, die

\footnotetext{
${ }^{46}$ Almor indica que su madre había muerto muy pronto y que no tenía recuerdos de ella. Su educación dependía entonces únicamente de la figura paterna.

${ }^{47}$ GÜNDERRODE, Karoline von, Sämtliche Werke und ausgewählte Studien, I Text, edición de Walter Morgenthaler, Karin Obermeier y Marianne Graf. Basel, Stroemfeld/Roter Stern, 1990. Aquí pág. 303.

${ }^{48}$ Ibidem, pág. 303.

Futhark 7 (2012)

Bascoy, La dimensión religiosa, 9-42
}

ISSN 1886-9300 
Religionen seyen zwar nützliche politische Einrichtungen, allein für den einzelnen Aufgeklärten höchst überflüßig" "49. Con esta afirmación se hace referencia a dos formas de entender la religión. Por una parte, las religiones tradicionales cumplen una función determinada en el entramado social como instituciones socio-políticas. Pero, por otro lado, el concepto que tanto Schleiermacher como Günderrode defienden de la esfera religiosa individual es obviado por el padre de Almor, quien figura en el texto como representante del pensamiento ilustrado. Lo mismo sucede a aquellos a quienes Schleiermacher se dirige y a quienes critica al comienzo de su primer discurso. Si el padre observa la religión únicamente desde su utilidad como institución, la atención al culto mahometano y a sus ceremoniales debe entenderse como un mero acto social. Al introducir este aspecto, Günderrode denuncia la vacuidad del culto desligado de una verdadera religiosidad. Esta misma crítica está presente en los textos de Schleiermacher, quien lamenta la pérdida del vínculo originario entre el ser humano y la deidad -lo que constituye la verdadera experiencia religiosa- de modo que la religión queda reducida a su visibilidad, es decir, a sus ropajes externos. Será a lo largo del proceso evolutivo de Almor, cuando este descubra la verdadera dimensión religiosa del ser humano.

Tras una infancia marcada por la indiferencia hacia el mundo, Almor experimenta durante su juventud una fase vital carente aún de espiritualidad. El protagonista admite que en su etapa de aprendiz de comerciante solamente se preocupaba por las ganancias y por gastar después su dinero "auf eine angenehme $\mathrm{Art}^{\prime 50}$. Europa y el ambiente de la gran ciudad son contrapuestos en el texto a la cultura oriental de la que proviene el protagonista. Occidente se identifica con el orden burgués y con su falsa moralidad, ejemplificada aquí en el comportamiento de una juventud que no respeta principios éticos. El narrador realiza un análisis crítico de su pasado y señala que, a pesar de los vicios a los que se rinde durante su estancia en la ciudad, abrumado por las cosas materiales, no consigue adaptarse del todo a esta forma de existencia, puesto que -dice refiriéndose al estilo de vida oriental"unsere Lebensart ist sehr ungesellig" ${ }^{\text {"11 }}$. La polaridad que la autora establece entre Occidente y Oriente es fundamental en el texto,

\footnotetext{
${ }^{49}$ Ibidem, pág. 303.

50 Ibidem, pág. 304.

51 Ibidem, pág. 304.

Futhark 7 (2012)

ISSN 1886-9300
}

Bascoy, La dimensión religiosa, 9-42 
puesto que Günderrode sitúa el principio de la religión en la geografía oriental, siendo imprescindible el retorno de Almor a su tierra para descubrirla. Mientras que Europa se asocia con una visión del mundo moderna, racional y materialista, Oriente representa el origen de la humanidad y aquello que la sociedad occidental ha perdido: el contacto con la naturaleza, la espiritualidad y la religión. La autora proyecta en la India su deseo, propio del pensamiento romántico, de alcanzar una existencia individual en la que se haya recuperado la verdadera esencia del ser humano, de la que forma parte la dimensión religiosa. A esta fase llegará Almor finalmente a través de su relación con el viejo brahmán, narrada en la última parte del texto. El brahmán le explica al protagonista que, mientras Europa, la cuna del pensamiento ilustrado, es considerada por sus ciudadanos como el centro del mundo, en la India, madre de una cultura mucho más antigua que la europea, es donde está arraigado el pasado del ser humano. Hacia el final del relato, la autora hace hincapié de nuevo en esta misma idea al describir la cultura europea como una cultura colonizadora que desprecia los verdaderos orígenes del mundo: "Der Nebel der Vergessenheit umschleiyert die Gräber unserer Vorwelt, nur wenige große Gestalten schimmern hindurch"52.

Almor cuestiona por primera vez su comportamiento materialista cuando percibe que su propia indiferencia ante la noticia de la muerte de su padre es una actitud reprochable. Esta falta de sensibilidad provoca en él un conflicto moral. Junto a ello, la ruina económica del comerciante para el que trabaja permite al protagonista experimentar la fugacidad de los bienes materiales. Ambos acontecimientos le llevan a reflexionar sobre su actitud y su forma de vida, contribuyendo, como él mismo indica, a despertar su espíritu de su letargo ${ }^{53}$. Mientras que hasta ese momento Almor había contemplado el mundo de un modo más instintivo -"mehr mit den Augen, als mit dem Geiste" ${ }^{24}-$, a partir de entonces inicia un proceso de reflexión en el que va a hacerse preguntas sobre su papel como ciudadano y sobre su propia naturaleza individual. El protagonista siente la necesidad de averiguar qué hay más allá de

\footnotetext{
${ }^{52}$ Ibidem, pág. 312.

${ }^{53}$ Ibidem, pág. 304.

${ }^{54}$ Ibidem, pág. 304.

Futhark 7 (2012)

ISSN 1886-9300
} 
las riquezas y de los placeres de los sentidos, comenzando así su desarrollo espiritual y la búsqueda de su propia identidad ${ }^{55}$.

En la primera fase del proceso evolutivo del protagonista se diferencian dos momentos, en los que Almor descubre su entorno social desde la moral y la razón ${ }^{56}$. Lo primero a lo que dirige su atención son las relaciones entre los seres humanos: lo que él denomina "die moralische Welt" ${ }^{\text {"57 }}$. La sociedad es concebida como una comunidad de individuos en la que las acciones de cada uno de ellos repercuten en el resto. Para alcanzar la armonía del conjunto social es preciso que la persecución del bien colectivo sea el objeto de la ambición particular de cada ciudadano. Al tratar de definir su identidad centrándose en sí mismo, Almor descubre que para lograr su propio bienestar espiritual debe desarrollar dos cualidades esenciales: la sabiduría y la virtud ${ }^{58}$. Ello exige el dominio de los sentidos y de las pasiones, así como la orientación de sus capacidades hacia la realización de una actividad útil. Al considerarse como ciudadano, Almor debe respetar el orden moral que rige en el marco de la comunidad, supeditando su propio bienestar personal a la voluntad común: "Betrachtete ich mich als Bürger des moralischen Reiches, so fand ich mich verpflichtet, dessen Wohlfahrt wie die eigene, nach allen Kräften zu befördern, ihr alles zu opfern, und mich als ihr Eigenthum zu betrachten"59. La superación del individualismo egoísta de la etapa en la que Almor vivía según las directrices de sus instintos, le conduce a una forma de existencia en la que tiene lugar un ensanchamiento del espíritu y en la que él mismo determina el objeto de su actividad en función del bien común. Pero la verdadera naturaleza individual permanece todavía oculta para el protagonista, puesto que, al definir al individuo como una propiedad de la sociedad, la autora está denunciando la negación de la personalidad individual a la que se ve sometido el ser

\footnotetext{
${ }^{55}$ Para expresar este cambio en su forma de percibir la realidad, Almor emplea la metáfora de una cueva, que es su propio interior, de la que surgen numerosos pensamientos, como si se tratase del agua que emana de una fuente.

56 Como ha señalado Christmann, Günderrode hace referencia aquí a la determinación del individuo como ser humano en base a los postulados de Kant vertidos en su filolosofía de la moral y de la razón práctica, englobando esta visión dentro de la concepción burguesa de la sociedad. CHRISTMANN, pág. 236.

${ }^{57}$ GüNDERRODE, 1990, pág. 304. Karoline von Günderrode aplica a esta concepción el principio de causa y efecto que rige en la naturaleza -Wirkund und Gegenwirkung- y al que también Schleiermacher se refiere en "Über das Wesen der Religion".

${ }^{58}$ Ibidem, pág. 305.

59 Ibidem, pág. 305.

Futhark 7 (2012)

Bascoy, La dimensión religiosa, 9-42
}

ISSN 1886-9300 
humano bajo las leyes del orden social y moral burgués. A pesar de que Günderrode no niega la importancia de la moral, al señalar la contraposición entre el orden social y la voluntad individual, está reclamando una nueva concepción del ser humano en la que su identidad no esté únicamente supeditada al orden moral.

Tampoco el acercamiento al entorno y a sí mismo desde la razón permite al protagonista descubrir su verdadera identidad y su papel social, dado que va a sufrir constantes contradicciones entre su propia naturaleza individual y los preceptos de la razón, que se obstina en cuestionarlo todo. Almor no es capaz de descubrir la dimensión religiosa de la existencia por medio de la moral y de la razón: "Durch sorgfältige Betrachtung lernte ich bald alles Menschliche im Menschen kennen, aber das Göttliche war mir noch nicht offenbar"60. El concepto de humanidad empleado por Günderrode en el texto se refiere a la esfera de la existencia humana diferenciada tanto de la animal o natural como de la divina. La autora introduce también el término 'Humanität' -como sinónimo de 'das Menschliche'- con el que define la parte propiamente humana del individuo, es decir, la que se corresponde con el desarrollo de la existencia social. La humanidad es para Günderrode "Sittlichkeit und Kultur"61. En el desarrollo de la dimensión propiamente humana de la existencia es necesaria la contemplación de las normas morales. Pero en ningún caso la moral puede entenderse como uno de los pilares de la religión. Al igual que Schleiermacher, la autora contrapone estos dos ámbitos: "Die Religion / ist nicht spekulativ wie die / Metaph[i]ysik, noch praktisch, / wie die Moral, ihr Wesen / ist nicht Denken, noch Handeln / sondern Anschauung u Gefüh",62. La diferencia del ámbito de la moral y la razón frente al de la religión es una idea que, como se observa en la cita anterior, es apuntada por Günderrode en sus notas sobre el discurso "Über das Wesen der Religion" y que explica y defiende a lo largo del relato. La necesidad de superar las limitaciones de la dimensión humana o social es percibida por Almor cuando, de forma intuitiva, es consciente de que hay una parte de sí mismo que hasta ahora ha permanecido oprimida u oculta:

[...] endlich sprach eine innere Stimme zu mir: Warum ist denn alles gut, was auf Erden ist, nur der Mensch nicht?

\footnotetext{
${ }^{60}$ Ibidem, pág. 305.

${ }^{61}$ Ibidem, pág. 310.

62 GüNDERRODE, 1991, pág. 282.

Futhark 7 (2012)
}

Bascoy, La dimensión religiosa, 9-42

ISSN 1886-9300 


\begin{abstract}
Warum soll er allein anders werden, als er ist? [...] Ich konnte dieser Stimme nichts entgegensetzen, als die Unordnung, in welche die moralische Welt gerathen würde, wenn keiner gegen seine Neigungen kämpfen wollte. Aber diese Antwort gnügte mir nicht; der Friede, mit solchen Opfern erkauft, war mir zu theuer, und ich konnte den Gedanken nicht mehr ertragen, mich Theilweise zu vernichten, um mich Theilweise desto besser erhalten zu können. Wie kann ich wissen, fuhr ich zu denken fort, was zu der eigentlichen Natur und Harmonie meines Wesens gehört, und was durch Erziehung und Verhältnisse Fremdes in mich übertragen wurde ${ }^{63}$
\end{abstract}

Mientras que los principios morales y los preceptos de la razón pertenecen al ámbito de la dimensión social del individuo, no actúan, sin embargo, en la esfera de la religión. La voz interior de Almor le revela que su verdadera naturaleza alcanza más allá de su dimensión social. Günderrode critica en el fragmento anterior la determinación del ser humano por medio de la educación y la cultura. Ambas modulan la identidad del ser humano en el ámbito social y reprimen, atendiendo al orden moral y a la razón, tanto su parte instintiva como su parte divina. Por ello la autora manifiesta a través de la figura de Almor la necesidad de realización plena de la existencia humana y, en tanto que contrapone moral y razón a la religión, subraya la imposibilidad de alcanzarla sin el desarrollo de la dimensión religiosa. El reclamo de su voz interior es el impulso que lleva al protagonista a despojarse de la cultura y a aislarse para poder contemplar su propio espíritu sin la influencia de la sociedad. Almor decide regresar entonces a su tierra natal y con este viaje finaliza la primera etapa de su desarrollo.

A su llegada a la costa de Siria, el protagonista encuentra una inscripción -cuyo texto no revela- y que presenta esa tierra como el lugar en el que desde siempre han convivido lo terrenal y lo celestial, lo humano y lo divino ${ }^{64}$. De nuevo Günderrode contrapone Occidente y Oriente, situando los orígenes de la religión en este último. La negación de la verdadera identidad que suponía el sometimiento al orden social burgués, lleva al protagonista a despojarse, tras su viaje, de todo lo adquirido durante la etapa en Europa y a elegir una vida solitaria, en contacto con la naturaleza y consigo mismo. Esta elección no es comprendida por su discípulo. Lubar equipara el aislamiento con el suicidio, puesto que, según él,

\footnotetext{
${ }^{63}$ GÜNDERRODE, 1990, págs. 305-306.

${ }^{64}$ Ibidem, pág. 306.

Futhark 7 (2012)

Bascoy, La dimensión religiosa, 9-42

ISSN 1886-9300
} 
ambas actuaciones contradicen el sentido de la sociedad y no son beneficiosas para ella. Almor le explica que solamente algunos individuos toman este tipo de decisiones, "denn so verschieden die äußere Bildung der Menschen ist, so verschieden ist auch ihre innere Natur, ihr Leben und ihre Wünsche",65. Günderrode subraya en esta cita la concepción romántica individualista y el ideal de la libertad del sujeto para definir su propia existencia. Esto no significa, sin embargo, que la autora fomente el aislamiento como la única posibilidad de realización individual. En realidad, Almor se presenta a sí mismo como una excepción, coincidiendo con la observación de Schleiermacher de que no todos, sino sólo algunos individuos eligen el camino de la religión. En su soledad, el protagonista es capaz de encontrarse a sí mismo a través de la contemplación y puede escuchar su voz interior, ajeno a las contradicciones de la vida social, algo que no le sería posible en el seno de la comunidad: "Hier in dieser stillen Einsamkeit habe ich meine Eigenheit, meinen Frieden, meinen Gott gefunden, und tausend Geisterstimmen reden Offenbarungen zu mir, die ich im Getümmel des Lebens nicht vernehmen könnte" ${ }^{\prime \prime 6}$. La liberación de los vínculos sociales es para Günderrode un requisito imprescindible para alcanzar la religión. Pero, mientras que Schleiermacher admite el papel de la religión en el ámbito social una vez recuperado su sentido verdadero, la escritora presenta en este relato su escepticismo hacia la integración de ambas dimensiones de la existencia. Günderrode se muestra muy crítica con el mundo en el que vive y manifiesta tanto su propia insatisfacción como su deseo de regreso al infinito, proyectando ambos en la figura de Almor.

El descubrimiento de la dimensión religiosa y su relevancia para lograr el pleno desarrollo de la existencia humana constituyen el tema central de "Geschichte eines Braminen". Günderrode diferencia claramente y en varias ocasiones a lo largo del relato entre la dimensión humana o social de la existencia y la religiosa. La autora atribuye a cada una un orden distinto, apoyándose para ello en las teorías de Schleiermacher:

Schon lange war es mir klar geworden, daß das Recht der Grund der bürgerlichen, und die Sittlichkeit der Grund der menschlichen Gesellschaft seyen. [...] jetzt entdecke ich Anlagen in mir, denen diese endlichen Beziehungen nicht

\footnotetext{
${ }^{65}$ Ibidem, pág. 307.

${ }^{66}$ Ibidem, pág. 307.

Futhark 7 (2012)

ISSN 1886-9300
}

Bascoy, La dimensión religiosa, 9-42 
mehr genügen wollten, mein Verstand wollte immer mehr und unersättlich wissen, meine Einbildungskraft suchte ein weiteres Feld für ihre Schöpfungen, meine Begierde einen unendlichen Gegenstand ihres Strebens, und mein innerer Sinn ahndete eine unsichtbare und geheimnißvolle Verbindung mit Etwas, das ich noch nicht kannte, und dem ich gerne Gestalt und Namen gegeben hätte ${ }^{67}$.

El sentido interno es un órgano de conocimiento de carácter intuitivo que Günderrode introduce en este fragmento como el órgano de la religión. Al igual que en las teorías de Schleiermacher, en las que esta capacidad es denominada el 'sentido' para la religión, se trata de una facultad no racional, innata en el ser humano, pero que no todos los individuos descubren por sí mismos. El sentido interno orienta al protagonista hacia 'algo' que está por encima de las relaciones sociales y que sólo puede alcanzar gracias a la religión: "sie [die Religion] sucht im / Menschen noch einen höhern / Charakter als sein $\langle\mathrm{e}\rangle$ Mensch- / heit [...]"68. Almor experimenta a partir de este momento un fuerte deseo de unidad con el universo, de infinitud, de huir de la limitación humana que implica lo terrenal ${ }^{69}$.

En su búsqueda de la divinidad, el protagonista se acerca en un primer momento a la naturaleza, en la que descubre una fuerza primigenia que está presente en todo el universo -lo que Schleiermacher denomina el espíritu del mundo. El entorno natural actúa como estímulo en el acto de contemplación por el que el protagonista percibe la existencia de dicha fuerza. El resultado de este acto sería lo que en las teorías de Schleiermacher se corresponde con una percepción religiosa. Almor describe dos momentos complementarios en este proceso: por una parte, su propio deseo le empuja hacia el infinito y, por otro lado, la misma acción del espíritu del mundo se manifiesta a él por medio del lenguaje de la naturaleza, es decir, del amor: "In dieser Sehnsucht, in dieser Liebe sprach der Naturgeist zu mir, ich hörte seine Stimme wohl, aber ich wußte noch nicht, wo sie herkämme; je mehr ich aber

\footnotetext{
${ }^{67}$ Ibidem, págs. 307-308.

68 GÜNDERRODE, 1991, pág. 285.

69 Este deseo de retorno a la unidad primigenia del universo es tematizado ya por Günderrode en un texto anterior, "Ein apokalyptisches Fragment", al que recuerdan las imágenes presentadas en "Geschichte eines Braminen". GüNDERRODE, 1990, págs. 52-54. La unión mística con la naturelaza es un tema que se repite a lo largo de la obra de Günderrode y que se integra en la concepción religiosa de la autora.

Futhark 7 (2012)

Bascoy, La dimensión religiosa, 9-42
}

ISSN 1886-9300 
darauf lauschte, desto deutlicher war es mir, daß es eine Grundkraft gäbe, in welcher Alle, Sichtbare und Unsichtbare, verbunden seyen" ${ }^{, 70}$. Günderrode se remite de nuevo aquí a las teorías de Schleiermacher para definir la totalidad como la unión de lo limitado y lo ilimitado, que puede percibirse por medio de la contemplación del entorno. En este contexto, el amor tiene un papel esencial como medio de comunicación entre el espíritu de la naturaleza o el espíritu del mundo y el individuo. Al inicio del relato, Günderrode destaca ya la relevancia del amor como lenguaje. Puesto que se trata de una fuerza unificadora que actúa entre lo finito y lo infinito, el amor supone la atracción entre la totalidad y los seres únicos. Es a través del lenguaje del amor, es decir, de la actuación de la fuerza o vida primigenia -la autora utiliza estos términos como sinónimos- cómo la naturaleza ayuda al individuo a tener de forma inconsciente o intuitiva la primera percepción religiosa. En sus notas sobre los discursos de Schleiermacher, Günderrode recoge las dos fases indicadas por el filósofo en el proceso de desarrollo religioso: en la primera de ellas se obtiene la percepción de la acción del espíritu del mundo en la naturaleza y la percepción de la humanidad ${ }^{71}$. Si bien el protagonista ha superado esta fase, llega a la conclusión de que únicamente puede lograr lo más elevado, "zu ihr aufzusteigen, von dem Irdischen zum Himmlischen", gracias a la verdadera religión ${ }^{72}$.

Tras este descubrimiento, el interés de Almor por la dimensión religiosa le lleva a ocuparse del estudio de los testimonios y escritos de las grandes religiones, de las palabras de quienes él denomina "Religionsdarsteller" todos ellos se muestra el mismo espíritu de formas distintas y con un único sentido, que coincide con sus propias percepciones. La autora comparte así con Schleiermacher la concepción de que las religiones no son más que manifestaciones diversas de un mismo sentimiento religioso: el de la unidad del universo. En relación con esto cabe mencionar que, aunque Günderrode no trata de modo explícito la idea de Schleiermacher de que no es imprescindible la imagen de dios en la religión, la autora no se apoya tampoco en una única representación de la divinidad. Así en el texto son utilizados distintos términos como fuerza primigenia, dios, deidad, lo infinito o

\footnotetext{
${ }^{70}$ Ibidem, pág. 308.

${ }^{71}$ GÜNDERRODE, 1991, págs. 284-285.

${ }^{72}$ GÜNDERRODE, 1990, pág. 308.

${ }^{73}$ Ibidem, pág. 309.

Futhark 7 (2012)
}

ISSN 1886-9300 
el espíritu del mundo para referirse a la divinidad, entendida como el infinito de Schleiermacher. Al tratar de explicarle Almor a Lubar el sentido de la religión, Günderrode introduce además otro concepto de las teorías del filósofo: la figura del mediador. Si bien el protagonista no ha necesitado ayuda para despertar su sentido de la religión, él mismo desempeña en el texto la función mediadora con respecto a su interlocutor al narrar su biografía espiritual:

Du verlangst von mir, junger Freund! daß ich dich einführe in die Thore des ewigen Tempels der Religion. Wisse! seine Aufschrift ist Unendlichkeit, und die Sprache ist endlich. Doch will ich versuchen, die heilige Bildsäule der Isis zu Sais, (unter der die Worte: "Ich bin, was da ist, was war und seyn wird“ standen,) vor dir zu entschleyern; so dir aber der innere Sinn nicht aufgeht für die Göttin, so wirst du sie nicht schauen, weder durch deine Vernunft, noch durch dein Wissen ${ }^{74}$.

Günderrode coincide con Schleiermacher en observar la dificultad para transmitir el sentimiento religioso por medio de la palabra, debido a la pérdida de inmediatez de la percepción del infinito al traducirla al lenguaje finito. A pesar de este problema, Almor tiene, al igual que el autor de los discursos, la intención de comunicar a su público el verdadero sentido de la religión ${ }^{75}$. En primer lugar, el protagonista subraya ante Lubar la principal dificultad para alcanzar la religión, para lo que hace referencia al símbolo de la columna de $I \mathrm{sis}^{76}$, que representa la infinitud del universo. Para desvelar la inscripción que se haya en la columna, no sirven ni la razón ni el conocimiento, puesto que solo se puede descifrar gracias al sentido interno.

Una vez activada la capacidad innata para la religión, el ser humano está preparado para contemplar la unidad del universo, tanto en sus manifestaciones actuales como a través de la historia. Günderrode, del mismo modo que Schleiermacher, concibe el desarrollo del mundo como un proceso de cambio constante, impulsado por el principio de transformación. La multiplicidad de los seres finitos que lo componen es generada por la misma unidad

\footnotetext{
${ }^{74}$ Ibidem, pág. 309.

75 También el texto cumple, como testimonio de una experiencia religiosa, la misma función mediadora que los discursos de Schleiermacher de cara al público lector, como se ha indicado sobre la obra del filósofo.

${ }^{76}$ Sobre este símbolo véase LICHER, Lucia M., Mein Leben in einer bleibenden Form aussprechen. Umrisse einer Ästhetik im Werk Karoline von Günderrodes (1780-1806), Heidelberg, C. Winter, 1996, págs. 78-119.

Futhark 7 (2012)

Bascoy, La dimensión religiosa, 9-42
}

ISSN 1886-9300 
primigenia o fuerza creadora, „der Grund aller Dinge“, que se mantiene infinita, dice Almor, „bey allem Wandeln und Sterben“"77. Y todas sus partes, entre las que se incluye cada ser humano individual, son un reflejo del mismo. La contemplación o "Anschauung" -Günderrode utiliza en el relato el mismo término acuñado por Schleiermacher en sus discursos- permite al ser humano obtener percepciones religiosas de la unidad del universo. Estas tienen, sin embargo, carácter subjetivo, puesto que el órgano innato para la religión procede del interior de cada individuo, siendo cada uno de ellos diferente a los demás:

Diese Anschauung der Dinge, die Anschauung ihres Urgrundes, ist die innerste Seele der Religionen, verschieden individualisiert in jedem Individuum; aber durchgehe sie selbst die Religionssysteme alle, in allen wirst du finden ein Unendliches, Unsichtbares, aus dem das Endliche und Sichtbare hervorging, ein Göttliches, das Mensch wurde, ein Uebergehen aus dem zeitlichen Leben in das ewige ${ }^{79}$.

En este fragmento, Günderrode expone una de las ideas que extrae de sus lecturas de los discursos: "Da die Religion / aber weder Geseze noch / Formeln, noch Systeme / hat so wird iede[rh]s Individu- / um eine eigne Religion, / eine eigne Anschauung des / Universums haben, die / doch wieder eine Ganzes ist / eine manichfache unendliche / Wirkung des Universums"80. Al igual que Schleiermacher, la autora defiende la concepción de la religión individual y la existencia de una única divinidad, es decir, el infinito, del que forman parte todos los seres individuales. La infinitud del universo, es decir, lo divino es también el mismo en todas las religiones, pero en cada una de ellas representado de modo diferente.

Si bien el estudio de las grandes religiones ayuda al protagonista a reafirmar su propia experiencia religiosa, estas no constituyen, sin embargo, un acceso directo a la religión, debido a que solo es posible llegar a ella por medio de la percepción individual y subjetiva del universo. A partir de este momento, todo lo que es limitado o contradice la unidad deja de tener relevancia para el protagonista. Aunque en la primera etapa de su desarrollo se

\footnotetext{
${ }^{77}$ GÜNDERRODE, 1990, pág. 309.

${ }^{78}$ Véase también, GÜNDERRODE, 1991, pág. 282.

${ }^{79}$ GÜNDERRODE, 1991, págs. 309-310.

${ }^{80}$ GündeRRODE, 1990, pág. 283.

Futhark 7 (2012)

ISSN 1886-9300
}

Bascoy, La dimensión religiosa, 9-42 
entrega a la comprensión del mundo desde el orden social y moral, ahora muestra su desacuerdo con la visión de la realidad que fomenta el orden burgués. Almor critica, por un lado, la consideración del individuo como un medio para el bien de la comunidad y no como fin en sí mismo. Por otra parte, el acercamiento al entorno que solo pretende encontrar las reglas que explican el orden de sus elementos individuales es rechazado por el protagonista, quien ahora se aproxima a la naturaleza desde la religión. Günderrode defiende en "Geschichte eines Braminen" la libertad individual del sujeto en lo que respecta al desarrollo de su espíritu, es decir, de su verdadera individualidad. Mientras que la actuación del ciudadano debe ajustarse a las leyes que regulan la vida social -es decir, la vida limitada-, debe respetarse a su vez la propia naturaleza individual del ser humano. Solo de este modo es posible la aspiración del individuo a lo más elevado. A este afán de perfeccionamiento individual corresponderá finalmente un momento histórico, en el que todos los individuos hayan alcanzado dicha perfección y se establezca así la armonía tanto a nivel personal como social. La importancia de este proceso reside en la idea de la totalidad: "Eins werden in einem großen Einklang" 1 . El anhelo de esta época de perfección puede entenderse en el sentido de la nueva Edad de Oro ${ }^{82}$ que proclamaban los autores románticos.

El fomento de la dimensión religiosa no implica para la autora que deban descuidarse tampoco las relaciones del ser humano con la naturaleza y con la humanidad: "So lebt der Mensch dreyfach: thierisch, dies ist sein Verhältniß zur Erde; menschlich, dies ist seine Beziehung zur Menschheit; geistig, dies ist seine Beziehung zum Unendlichen, Göttlichen. Wer auf eine dieser drey Arten nicht lebt, hat eine Lücke in seiner Existenz, und es geht inm etwas verlohren von seinen Anlagen" ${ }^{\prime 3}$. En la primera forma de existencia, que podríamos denominar natural, la vida se rige por los instintos. En la segunda, la vida en comunidad, el ciudadano se orienta según las normas del orden moral, siendo relevante además en este ámbito el desarrollo del conocimiento. La tercera dimensión, la religiosa, es espiritual y está determinada por la percepción de lo infinito. El ser humano necesita en esta esfera "einen unendlichen

\footnotetext{
${ }^{81}$ GÜNDERRODE, 1991, pág. 310.

${ }^{82} \mathrm{La}$ idea de la nueva Edad de Oro está ligada al concepto de inmortalidad, que Günderrode introduce hacia el final del relato. Sobre este aspecto véase LICHER, págs. 388-396.

${ }^{83}$ GÜNDERRODE, 1990, pág. 311.

Futhark 7 (2012)

Bascoy, La dimensión religiosa, 9-42
}

ISSN 1886-9300 
Gegenstand der Betrachtung" hacia el que orientar su contemplación y cuyo alcance supone el perfeccionamiento individual ${ }^{84}$. Una vez descubierta la religión, el protagonista afirma que su visión del mundo ha cambiado y sitúa la religión en un nivel superior de la existencia humana: "Der Sinn für dies ewige Leben ist mir schon hier aufgegangen in religiöser Betrachtung, darum ist mir das Zeitliche in gewissem Sinne so gering geworden, und mein Geist hat die Dinge ganz anders geordnet" ${ }^{\prime 85}$.

La última etapa evolutiva de Almor se desarrolla en la India, donde el protagonista conoce a un sabio brahmán que le instruye sobre la ancestral cultura de su tierra. La descripción que Günderrode hace de este personaje muestra de nuevo el profundo conocimiento por parte de la autora de los discursos de Schleiermacher y su concordancia con las teorías del autor:

\begin{abstract}
Je mehr ich diesen Menschen kennen lernte, desto mehr fand ich einen wahren Priester, einen Mittler zwischen Gott und den Menschen in ihm. Göttliches und Menschliches waren in seinem Gemüthe auf das Innigste und Schönste verknüpft. Die Erde war ihm heilig wie ein Vorhof des Himmels, ihr buntes Getümmel verwirte inn nicht, alles entwickelte sich klar vor seinem Geiste, und er blieb rein und unschuldig in den Strudeln des Verderbens. [...] Er lehrte mich, wie in jedem Theile des unendlichen Naturgeistes die Anlage zu ewiger Vervollkommnung läge, wie die Kräfte wanderten durch alle Formen hindurch, bis sich Bewußtseyn und Gedanke im Menschen entwickelten; wie von dem Menschen an, eine unendliche Reihe von Wanderungen, die immer zu höherer Vollkommenheit führten, der Seelen warteten; wie sie endlich auf geheimnißvolle Weise sich alle vereinigten mit der Urkraft, von der sie ausgegangen, und Eins mit ihr würden, und doch zugleich sich selbst blieben, und so die Göttlichkeit und Universalität des Schöpfers mit der Individualität des Geschöpfes vereinigten. $\mathrm{Er}$ lehrte mich, wie eine Gemeinschaft bestehe zwischen den Menschen, denen der innere Sinn aufgegangen sey, und dem Weltgeiste ${ }^{86}$.
\end{abstract}

En esta descripción de la figura del brahmán, Günderrode retoma varias ideas acerca de la dimensión religiosa, que ya ha introducido a lo largo del relato. Para Almor el sabio es una figura

\footnotetext{
${ }^{84}$ Ibidem, pág. 311.

85 Ibidem, págs. 309-310.

${ }^{86}$ Ibidem, pág. 312.

Futhark 7 (2012)

ISSN 1886-9300
} 
mediadora, un sacerdote de la verdadera religión, puesto que posee la capacidad de acercar la divinidad, es decir, lo infinito, a los seres humanos. En él descubre una forma de existencia en la que el individuo puede vivir en armonía con el entorno, de modo que esta figura constituye un ejemplo de la verdadera existencia religiosa. EI brahmán se acerca a la realidad contemplándola desde la perspectiva de la religión, observando en cada elemento la acción del espíritu del mundo. La naturaleza es para él un antepatio de la divinidad. La autora emplea aquí el mismo término utilizado por Schleiermacher para definir la naturaleza como un espacio necesario para alcanzar la religión. En este fragmento, la autora establece además una correspondencia entre la idea de la transmigración de las almas y el concepto del cambio continuo del universo y la manifestación de su unidad a través de los seres individuales de la teoría schleiermacheriana. Como ha señalado ya Wolfgang Westphal ${ }^{87}$ en su análisis del texto, este es el elemento más importante del aprendizaje de Almor a través del brahmán: la unión de los seres humanos con la fuerza primigenia, la comunidad del individuo religioso con el espíritu del mundo. Universalidad e individualidad son condición propia del ser humano, puesto que es limitado y en su semejanza al universo, a su vez, ilimitado.

El último tema relativo a la religión que Günderrode trata en "Geschichte eines Braminen" es el concepto de la inmortalidad. Cuando el brahmán está a punto de morir, le pide a Almor que se ocupe del cuidado de su hija y de recordarle quien era, puesto que así continuará existiendo tanto en el amor como en la memoria de la niña y del propio Almor. Estos dos vínculos, el amor y el recuerdo, actúan después de la muerte y, al igual que Günderrode explica ya en el texto "Die Manen",88, permiten la continuación de la influencia de los antepasados en las generaciones posteriores. Con la muerte del brahmán la autora subraya la idea del retorno a la unidad primigenia tras la muerte, lo que representa lograr la perfección, es decir, alcanzar el absoluto. Mientras que Schleiermacher considera que es posible una forma de inmortalidad terrenal que se logra por medio de las vivencias religiosas, esta idea no es tratada por la autora en el relato. Günderrode centra su atención en mayor medida en la influencia del recuerdo de los antepasados como forma de eternidad. Como explica la autora en "Die Manen", al igual que en el

\footnotetext{
${ }^{87}$ WESTPHAL, pág. 143.

${ }^{88}$ GÜNDERRODE, 1990, págs. 30-35.

Futhark 7 (2012)
}

Bascoy, La dimensión religiosa, 9-42

ISSN 1886-9300 
ámbito de la religión es necesario el sentido interno para captar su presencia. Esta idea es enmarcada después en "Geschichte eines Braminen" en la exposición de la concepción religiosa. La relación entre el la idea de inmortalidad ligada y la concepción romántica de la religión, que Günderrode construye a partir de sus lecturas de Schleiermacher, no está claramente explicada, sin embargo, en el relato. Se puede interpretar que la memoria de los antepasados, que han regresado al origen, es decir, a la unión con la totalidad, actúa ahora desde la unidad del universo sobre el individuo. En este sentido, el concepto de historia de Günderrode coincide con el de Schleiermacher.

Aun teniendo en cuenta que hay algunas divergencias, como se ha señalado a lo largo del análisis, entre los conceptos de religión de Günderrode y de Schleiermacher, se puede observar hasta qué punto el diálogo intertextual con el autor es fundamental para interpretar el texto "Geschichte eines Braminen". La autora no solo comparte con el filósofo su concepto de la religión y muchas de sus ideas concretas, sino que utiliza también a menudo la misma terminología empleada por Schleiermacher en sus discursos. A la luz de la interpretación del relato realizada en este trabajo, puede afirmarse que Günderrode traslada al ámbito literario las teorías sobre la religión del autor.

En "Geschichte eines Braminen", Karoline von Günderrode muestra su pleno acuerdo con el deseo de Schleiermacher y, en general, de la primera etapa del Romanticismo alemán, de recuperar y fomentar la esfera religiosa de la existencia humana. Ambos autores comparten la idea de que la identidad del ser humano sólo puede ser determinada desde la propia individualidad y en la relación particular de cada individuo con la naturaleza, la humanidad y la divinidad, de forma que el desarrollo de estas tres dimensiones permite la realización de una existencia plena. Esta concepción individualista que defiende la escritora pone de manifiesto su orientación romántica antiburguesa. Günderrode presenta en este texto, así como en toda su obra, el orden social impuesto y las leyes morales que lo sustentan como un sistema opresor, que obliga al ser humano a negar parte de su propia naturaleza individual y, por tanto, de su verdadera identidad. La necesidad de recuperación de la dimensión religiosa del ser humano está vinculada en Günderrode y en Schleiermacher, así como en otros autores románticos, a la lucha contra una mentalidad antropocéntrica, materialista y racional, que 
amenaza con destruir la esfera de la espiritualidad propia del individuo. La dimensión religiosa de la existencia no puede estar tampoco supeditada a los dogmas y ritos de las grandes religiones, con los que se ha ido desvirtuando a lo largo de la historia el verdadero sentido de la religión. Esta debe ser, por el contrario, como parte intrínseca del sujeto, originariamente subjetiva, aunque sea posible y necesaria también la dimensión religiosa social, como se ha visto en Schleiermacher. La relación con la divinidad es personal e individualizada y a la vez común al resto de los individuos, puesto que solo existe una única religión verdadera. 